\title{
Activation of Substantia Nigra Neurons: Role in the Propagation of Seizures in Kindled Rats
}

\author{
Douglas W. Bonhaus, ${ }^{*} \dagger$ Judith R. Walters, $\neq$ and James O. McNamara ${ }^{\star}, \dagger$ \\ *Departments of Medicine (Neurology) and Pharmacology, Duke University Medical Center and †Epilepsy \\ Research Laboratory, Veterans Administration Medical Center, Durham, North Carolina 27705; and \$Experimental \\ Therapy Branch, National Institute of Neurological and Communication Disorders and Stroke (NINCDS), \\ Bethesda, Maryland 20205
}

\begin{abstract}
The substantia nigra (SN) is crucial to the propagation of seizures in kindled rats and in other experimental seizure models. However, the mechanisms by which the SN acts to facilitate the propagation of seizures are unknown. To investigate these mechanisms we (1) quantified the activity of SN neurons during seizures in kindled and naive rats in a paralyzed, ventilated state and (2) examined the relationship between activity of neurons in the SN and the seizure-facilitating action of this structure. Our principal findings were that (1) the majority of both SN dopamine and SN pars reticulata neurons, in kindled rats, fired in bursts temporally correlated to EEG waveforms recorded outside the SN during seizures; (2) this response was only rarely found in SN neurons of naive rats during seizures elicited by stimulation of the amygdala; (3) unlike kindled rats, lesions of the $\mathrm{SN}$ in naive rats did not suppress seizures.

The finding that $\mathrm{SN}$ neurons fired in bursts during seizures in kindled, but not naive, rats indicates that seizure activity propagated into SN only in kindled rats. The correlation between seizure-suppressant effects of lesions and SN activation during seizures leads us to propose that one mechanism by which the SN promotes seizure propagation involves SN activation and transmission of seizure activity to targets of $\mathrm{SN}$.
\end{abstract}

Kindling is an animal model of epilepsy (for a review, see McNamara et al., 1985). The term "kindling" refers to a phenomenon in which repeated administration of an initially subconvulsive electrical stimulus eventually results in intense limbic and clonic motor seizures (Goddard, 1967). In rats kindled by repeated stimulation of the amygdala, the initial stimulus evokes only a brief focal electrical seizure, termed "afterdischarge" (AD), without behavioral manifestations. Once established, the enhanced response to the initially subconvulsive stimulus is permanent (Goddard et al., 1969).

Several lines of evidence indicate that the substantia nigra $(\mathrm{SN})$ is crucial to the propagation of seizures in both kindled animals and other experimental models. Microinjection of muscimol, a GABA agonist, or gamma-vinyl GABA, a GABA-transaminase inhibitor, into the $\mathrm{SN}$, but not dorsal to the $\mathrm{SN}$, suppresses both electrically and chemically induced seizures (Gonzalez and Hettinger, 1984; Iadarola and Gale, 1982; Le

\footnotetext{
Received Jan. 21, 1986; revised Apr. 14, 1986; accepted May 15, 1986.

This work was supported by VA Medical Research funds and Postdoctoral Fellowship Award NS 07614 and Grant NS 17771 from the NIH. We thank Susan L. Bonhaus for her technical assistance and Ms. Eloise Pittman for her assistance in preparation of this manuscript.

Correspondence should be addressed to Douglas W. Bonhaus, Epilepsy Research Lab, Veterans Administration Medical Center, 508 Fulton Street, Durham, NC 27705.
}

Copyright (C) 1986 Society for Neuroscience $0270-6474 / 86 / 103024-07 \$ 02.00 / 0$
Gal la Salle et al., 1983; McNamara ct al., 1983, 1984). This anticonvulsant action is apparently mediated by suppression of neuronal activity in the SN, since microinjection of muscimol suppresses nigral unit activity (Waszczak et al., 1980) and also suppresses nigral output to superior colliculus (Hikosaka and Wurtz, 1985). The fact that destruction of the SN also protects against seizures (Garant and Gale, 1983; McNamara et al., 1984) further supports the idea that the anticonvulsant action is mediated by suppression of nigral neuronal activity.

These findings indicate that the $\mathrm{SN}$ facilitates the propagation of seizures, but they do not specify a mechanism of action. The SN may itself transmit seizure activity from rostral sites of origin to target structures. Alternatively, the SN, by means of its basal activity, may provide a tonic seizure-facilitating action on other pathways, through which the seizure is transmitted. We initiated investigations of these possibilities by recording single-unit activity of neurons in the SN through the course of electrically induced seizures in both naive and kindled rats. The findings of the single-unit studies led us to examine the effects of SN lesions on electrically induced seizures in the amygdala of naive rats.

\section{Materials and Methods}

\section{Stereotactic surgery}

Male Sprague-Dawley rats (Charles River Breeding Laboratories) were anesthetized with pentobarbital. A bipolar stimulating electrode was placed in the right amygdala, a monopolar electrode for recording electroencephalographic $(\mathrm{EEG})$ activity was placed in the right caudate, and an indifferent EEG reference source was obtained from a lead connected to a screw placed in the skull, as previously described (McNamara et al., 1984).

\section{Kindling}

Animals were maintained on a light (0700-1900)/dark (1900-0700) cycle. After a postoperative recovery period of at least $4 \mathrm{~d}$, constantcurrent stimulations (300-1000 $\mu \mathrm{A}, 1 \mathrm{msec}$, biphasic square wave pulses, $60 \mathrm{~Hz}$ for $1 \mathrm{sec}$ ) were delivered to the amygdala 5-7 times/d at interstimulus intervals of at least $90 \mathrm{~min}$. Animals were stimulated $7 \mathrm{~d}$ a week until 3 consecutive stimulations evoked a clonic motor seizure with rearing and falling (class 5 seizure, as described by Racine, 1972). A second group of animals was implanted with electrodes but not stimulated and was used as a naive control group.

\section{Extracellular recording}

Not less than $5 \mathrm{~d}$ after completion of kindling, animals were anesthetized with halothane and a cannula was inserted into the trachea. The animals were ventilated at a rate that maintained $\mathrm{CO}_{2}$ concentrations in the expired air at 3.5-4.5\%, as determined with an Infrared Products $\mathrm{CO}_{2}$ monitor. Body temperatures were maintained near $37^{\circ} \mathrm{C}$, using a temperature probe and an adjustable heating pad. While the rats were under halothane anesthesia, a burr hole was drilled in the skull overlying the 
left SN ( $3 \mathrm{~mm}$ anterior to lambda, $2 \mathrm{~mm}$ left of the central suture). Infiltration anesthesia (5-7 ml of $1.5 \%$ mepivacaine) was administered to all wound edges and pressure points. Animals were then paralyzed by tail vein injection of $0.3 \mathrm{ml}$ of gallamine $(20 \mathrm{mg} / \mathrm{ml})$ and ventilated with room air.

We emphasize that all surgical procedures were carried out under halothane anesthesia and that all animals were treated with the longacting infiltration anesthetic, mepivacaine. Recording sessions typically lasted $2.5 \mathrm{hr}$ or less. In paralyzed animals prepared exactly as described above, heart rate $(377.2 \pm 25.9$ beats $/ \mathrm{min} ; n=5)$ and mean arterial pressure $(116.0 \pm 6.3 \mathrm{~mm} \mathrm{Hg} ; n=5)$ gave no indication of undue stress, since these values fall within the normal range for untreated animals (Baker et al., 1979). These procedures were carried out in accordance with the guidelines for the care and use of laboratory animals established by the Institute of Laboratory Animal Resources (Moreland et al., 1978).

Extracellular single-unit recordings were made from SN neurons using glass pipette electrodes containing a thread of fiberglass and filled with $2.0 \%$ pontamine blue in $2 \mathrm{M} \mathrm{NaCl}(4-6 \mathrm{M} \Omega)$. Recordings were made from SN dopamine neurons and SN pars reticulata neurons (SNPR) tentatively identified on the basis of their waveform, firing rate, and location (Grace and Bunney, 1983; Guyenet and Aghajanian, 1978). Amplitude of the SN units was at least twice, and more typically 4 times baseline noise (Fig. 1).

Once a SNPR or a SN dopamine neuron was isolated, an electrical seizure was evoked by stimulating the contralateral amygdala $(1000 \mu \mathrm{A}$ $1 \mathrm{msec}$ pulses at $60 \mathrm{~Hz}$ for $2 \mathrm{sec}$ ). No more than $6 \mathrm{ADs}$ were evoked in any one animal during single-cell recording. The interval between AD-evoking stimulations was always at least $10 \mathrm{~min}$. In 4 cases the same cell was followed through multiple ADs. In all other cases, a different cell was selected prior to each evoked seizure. To determine whether electrical stimulation of the amygdala without associated $\mathrm{AD}$ would alter the firing rate of SN neurons, animals were stimulated with trains of electrical stimulation at current intensities insufficient to evoke AD (1 msec pulses, $60 \mathrm{~Hz}$, for $2 \mathrm{sec})$ or with single pulses of current at intensities that would evoke $\mathrm{AD}$ if given in a train $(1000 \mu \mathrm{A}, 1 \mathrm{msec}$, biphasic square wave).

To test whether the activities observed in the $\mathrm{SN}$ of kindled animals were common to all brain stem cells, we recorded unit activity of neurons located in pontine reticular formation caudal to the $\mathrm{SN}(0-1.3 \mathrm{~mm}$ posterior to lambda, $1.0-1.3 \mathrm{~mm}$ right of the central suture) at approximately the same dorsal/ventral level as the SN (7-10 mm from dura). These recordings in kindled rats were performed exactly as described above, except that tungsten microelectrodes (F. Haer; 2-4 M $\Omega$ ) were used.

Amplified EEG and single-unit signals were recorded on both tape and strip-chart recorders. Rate data were quantified using a Medical Systems International computer or an RC Electronics Computerscope. Examination of tape-recorded data for temporal correlations between nigral unit activity and EEG waveforms was performed by an investigator unaware of the experimental treatment (J.O.M.). The criterion for determining that a cell was firing in a manner temporally correlated to components of the EEG waveform was that the cell fire in bursts of 3 or more action potentials temporally associated with 3 or more consecutive EEG spikes during AD.

Recording sites were marked by iontophoretic dye injection using a DC current of $15 \mu \mathrm{A}$ for $15 \mathrm{~min}$ or, in the case of the metal electrodes, by a marking lesion made by application of $10 \mathrm{sec}$ of $100 \mu \mathrm{A}$ cathodal current. Animals were killed by a lethal dose of halothane.

\section{Histology}

Placements of bipolar stimulating electrodes in the right amygdala, EEG recording electrodes in the right caudate, and unit recording electrodes in the left SN were verified histologically. Brains were removed and stored in a fixative solution of sucrose and formalin, as described previously (Waszczak et al., 1980). Sections $40-\mu$ m-thick were cut on a freezing microtome and the location of the dye injection was determined. The sections were then stained for Nissl substance to better determine the location of stimulating and recording electrode tracks.

Animals were removed from the study if histologic evidence for the presence of stimulating electrodes within the amygdala or recording electrodes within the SN could not be obtained.

\section{SN lesion experiments}

Stimulating electrodes were placed in the right amygdala of naive SpragueDawley rats, as described above. At the time of electrode placement,
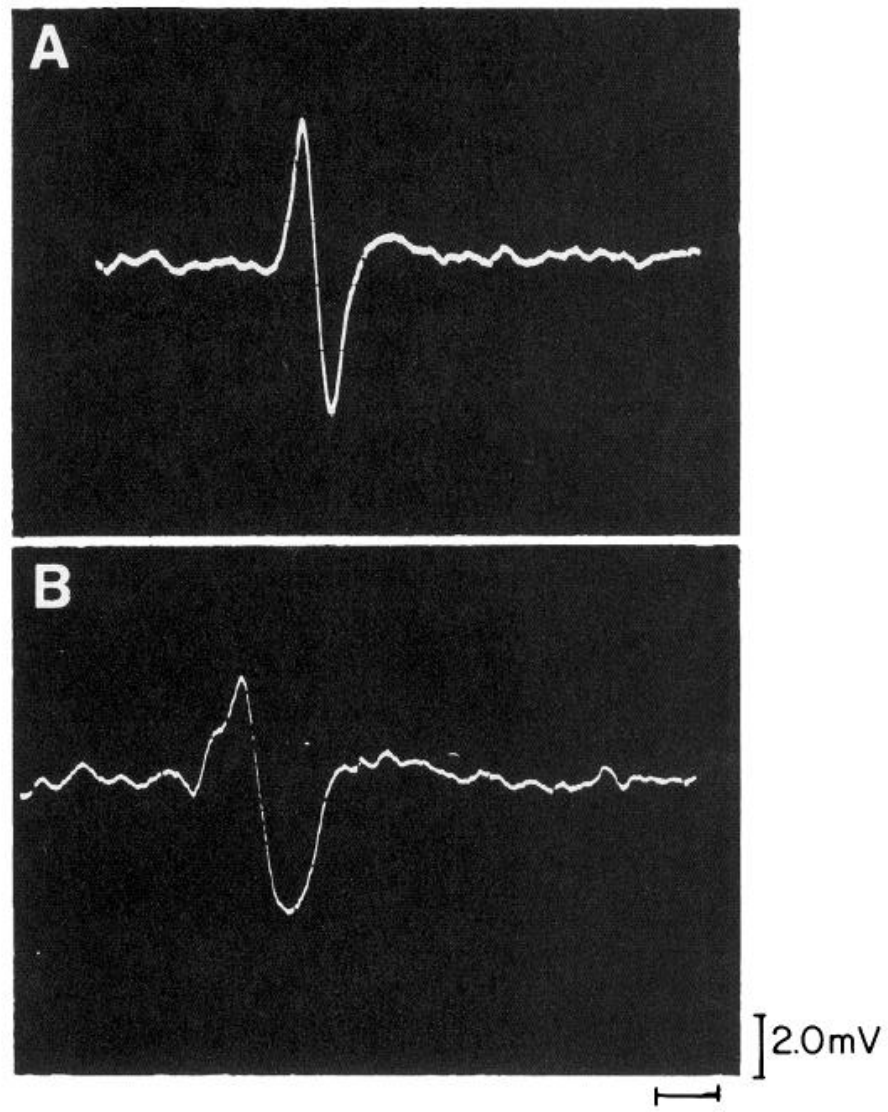

$1.0 \mathrm{~m} \mathrm{Sec}$.

Figure 1. SN neuron waveforms. A, Waveform of a neuron recorded in substantia nigra pars reticulata. $B$, Waveform of a neuron recorded in substantia nigra pars compacta. Signals were recorded through a World Precision Instruments amplifier. Low- and high-frequency cutoff filters were 100 and $5000 \mathrm{~Hz}$, respectively.

bilateral lesions of the $\mathrm{SN}$ were made by the microinjection of $30 \mathrm{nmol}$ of $N$-methyl-D,L-aspartate (NMDA) in $0.2 \mu l$ saline into each SN. Injections were made at a rate of $0.04 \mu \mathrm{l} / \mathrm{min}$ using a Harvard syringe pump. The injection cannula was removed 2 min after termination of the injection. Control animals received $0.2 \mu \mathrm{l}$ saline into the $\mathrm{SN}$.

Seven days after surgery, the effect of the nigral lesions on the duration of the evoked afterdischarge (ADD) and the threshold to evoke the AD (ADT) was determined in freely moving animals. ADT was determined by application of an incremental ascending ramp of current levels to the amygdala (100-800 $\mu \mathrm{A}$, biphasic square wave pulses of $1 \mathrm{msec}$ duration at $60 \mathrm{~Hz}$ for $1 \mathrm{sec}$ ). Current was incremented in $100 \mu \mathrm{A}$ steps at intervals of 1 min until an AD was evoked. ADD was determined by inspection of the EEG recorded from the amygdala referenced to a skull screw. The methodology used to assess the effects of nigral lesions on seizure propagation in previously kindled animals has been described in detail elsewhere (McNamara et al., 1984).

Lesion location and size were determined by histologic examination of coronal sections by an investigator unaware of the experimental results (J.O.M.). The cross-sectional area of the nigral destruction in each section was determined using a Videoplan digitizer pad (Carl Zeiss and Summagraphics Corporation). The volume of nigral destruction was then determined by summing the products of the cross-sectional area of destruction and the distance between sections. Only animals with lesions involving at least $25 \%$ of each side of the SN were included in the lesioned group.

\section{Statistics}

Values reported are the means and standard errors of the mean $(\bar{X} \pm$ $\mathrm{SE}$ ). Statistical differences between groups were determined using Student's $t$ test, chi-square analysis, or sign tests as appropriate (Armitage, 1971). The level of statistical significance was set at $p<0.05$. 


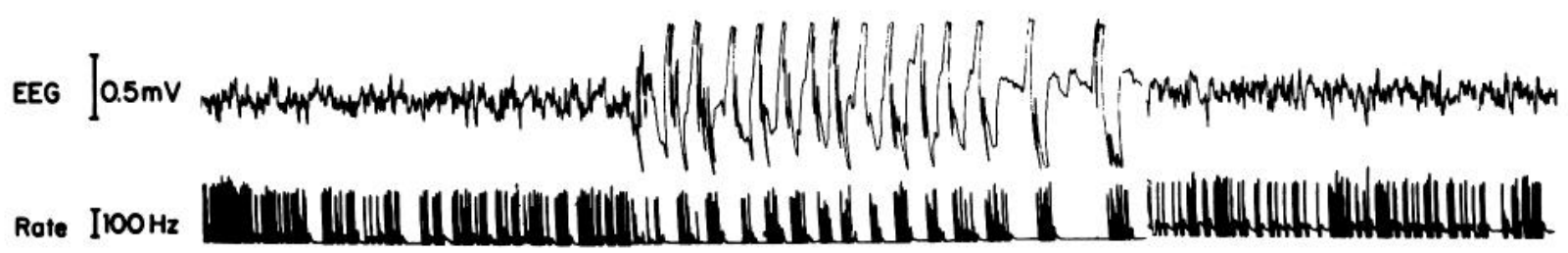

\section{Acc. Pulse

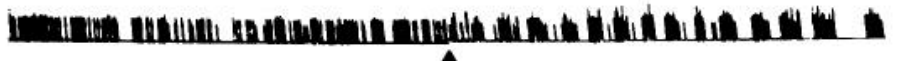 4

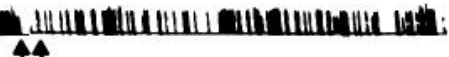

Time (sec)

Figure 2. A chart record of caudate EEG and the response of a SNPR neuron during AD evoked in a kindled rat. The upper trace is EEG recorded from the caudate; the second trace is the instantaneous firing rate of the SN neuron, based on the interval of the 2 most recent action potentials (inverse of interspike interval); the third trace is the unit acceptance pulses delivered from the window discriminator to mark the occurrence of an action potential. For graphic presentation, approximately $4 \mathrm{sec}$ of stimulus artifact are excised from each trace (arrow). To present activity after termination of the $\mathrm{AD}$, a second cut was made (double arrow). The presence of at least 3 action potentials per burst was verified by photographs such as those in Figure 3. It was determined that this cell was firing in bursts temporally correlated to EEG spikes during AD.

\section{Results}

\section{Seizure duration in paralyzed rats}

$\mathrm{AD}$ duration was shorter in the paralyzed than in the unrestrained condition. The AD duration of the final kindled seizure in the freely moving rat was $56 \pm 4 \mathrm{sec}$, compared to $31 \pm 7$ sec on the first $\mathrm{AD}$ subsequently evoked in the paralyzed state $(p<0.01)$. Despite this attenuation of AD duration in the paralyzed state, there was still a statistically significant difference between naive and kindled rats in the AD duration evoked in
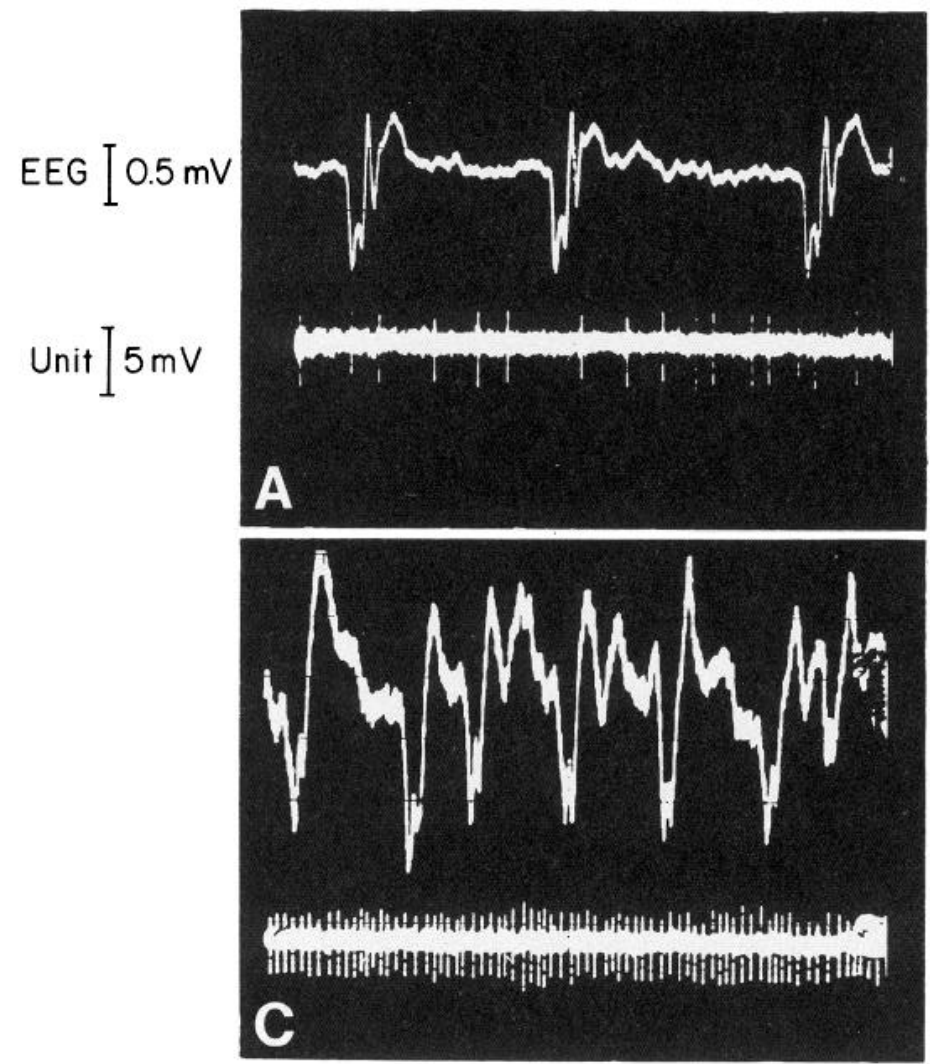
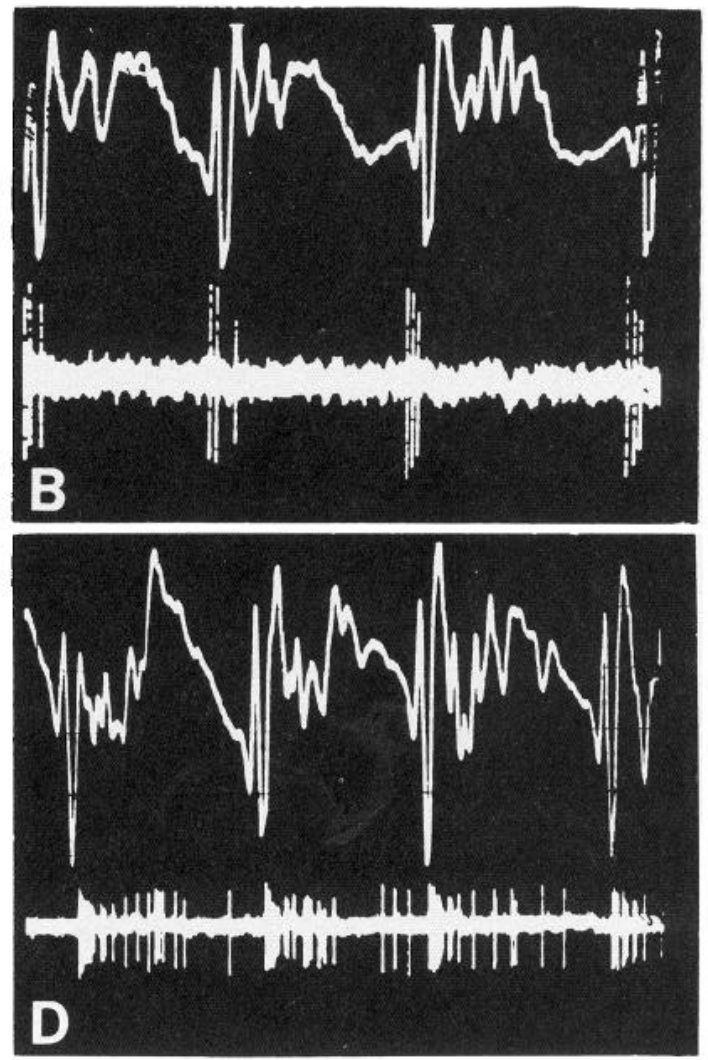

$0.2 \mathrm{sec}$

Figure 3. For each set of traces, the upper trace is EEG recorded from the caudate during $\mathrm{AD}$, and the second trace is the activity of a single $\mathrm{SN}$ neuron. $A$, Record from a SN dopamine neuron in a naive rat; it did not change its firing pattern during AD. $B$, Record from a SN dopamine neuron in a kindled rat; it fired in bursts during the spike portion of the EEG AD. $C$, Record from a SNPR neuron in a naive rat; it did not change firing pattern during the AD. $D$, Record of a SNPR neuron in a kindled rat; it was determined to fire in bursts during the spike portion of the EEG during AD. 


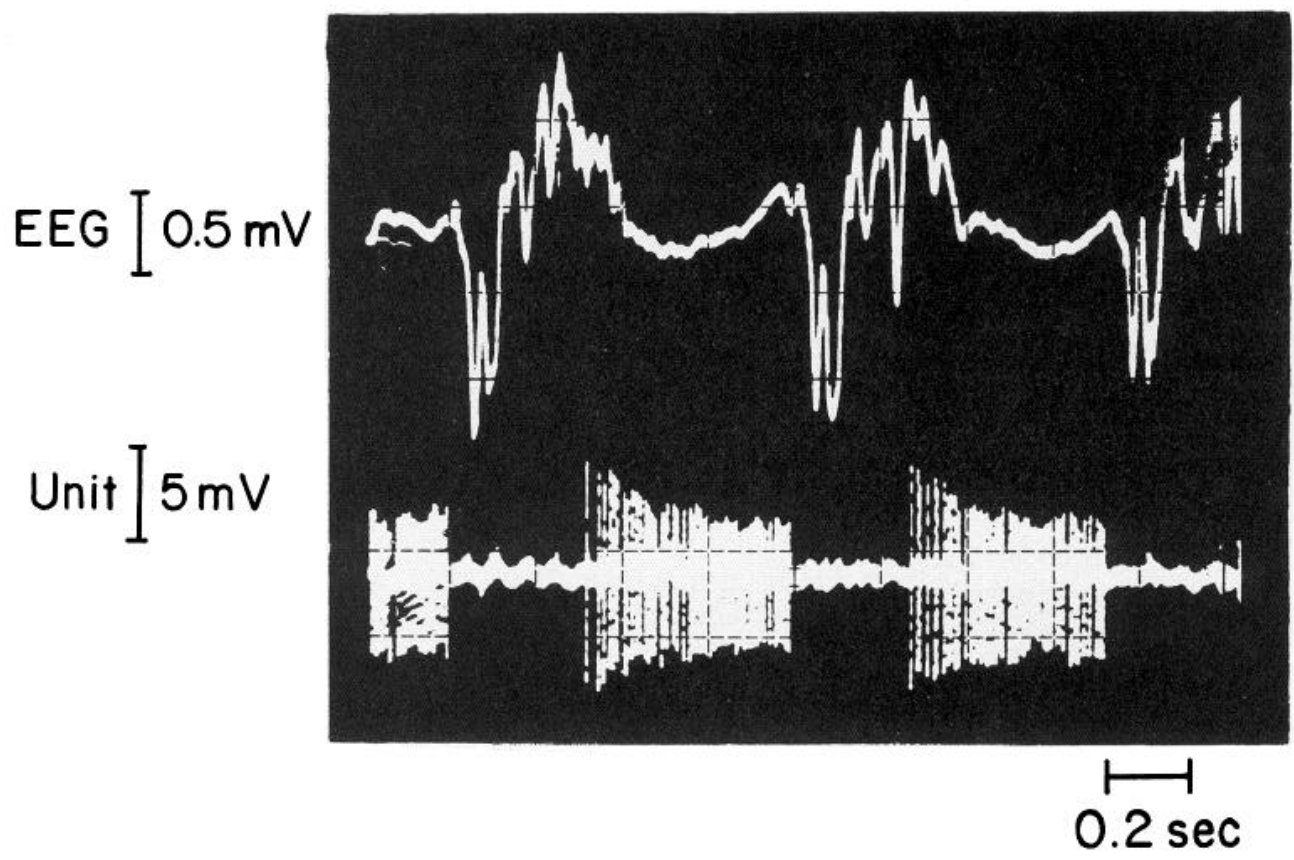

Figure 4. SNPR cell during AD. The upper trace is EEG recorded from the caudate during $\mathrm{AD}$. The second trace is the unit recording. This neuron was determined to fire in bursts during the slow-wave portion of the AD. the paralyzed condition. On the first AD evoked in the paralyzed state, $\mathrm{AD}$ duration in naive animals was $10 \pm 2 \sec (n=10)$, compared to $31 \pm 7 \sec (n=17)$ in kindled rats $(p<0.05)$.

\section{Unit activity in the $S N$ : Pattern}

Nigral neurons of kindled rats exhibited a striking change in firing pattern during AD. These cells fired in bursts of action potentials with the bursts temporally correlated to waveforms recorded in the EEG (Fig. 2). This change in firing pattern was found in both SNPR and SN dopamine neurons. The likelihood that SNPR units would fire in bursts time-locked to the EEG $\mathrm{AD}$ was far greater in kindled rats $(86 \%)$ than in naive rats $(20 \%)$ $(p<0.05)$ (Table 1). A similar trend was observed for the relatively few dopamine cells tested ( $p<0.1$ ) (Table 1, Fig. 3).

The bursts of action potentials generated in the SN during the AD constituted a dramatic change in spike frequency. The interspike interval of the nigral units during the bursts was 510 times shorter than the interspike interval of the cell recorded prior to the stimulation. As an example, the within-burst firing rate of the dopamine neuron in Figure $3 B$ (calculated during a typical burst) was 89 spikes/sec, compared to a prestimulus rate of 4 spikes/sec. The within-burst firing rate of the SNPR neuron in Figure $3 D$ was 250 spikes/sec, compared to a prestimulus rate of 25 spikes/sec. The apparent amplitude of the action potential decreased during these bursts.

The bursts of nigral units were temporally correlated to components of the EEG waveform recorded outside the $\mathrm{SN}$ (caudate or amygdala). Most nigral units were found to be correlated to the polyspike complex of the EEG during AD (Fig. 3, $B, D$ ). However, a minority of the SN cells were clearly correlated to the slow-wave portion of the AD (Fig. 4, Table 1). Cells held through multiple ADs were found to be time-locked to the same component of the waveform on each stimulation. In all cases, the burst-firing pattern terminated at the end of the recorded AD. Distortion of EEG waveforms at fast playback speeds precluded a more precise determination of the temporal relationship between the bursts of action potentials in the SN and individual spikes in the EEG waveform.

The bursting pattern almost always began at some point after the cessation of the stimulus train. Of all the cells recorded, only 2 began to fire in a burst pattern during the stimulus train. The latency from the time of onset of the $\mathrm{AD}$ to the time at which the cell began to fire in bursts varied from 0 to $30 \mathrm{sec}$.

Despite the observation that the burst-firing pattern became more intense throughout the course of the seizure (Fig. 5), the difference between naive and kindled rats regarding the likelihood that a nigral unit would fire in bursts time-locked to the EEG AD was not merely a function of differences in AD duration. During the initial $10 \mathrm{sec}$ of AD, $17 \%$ of the SNPR cells in naive rats were found to be firing in a bursting pattern, whereas, in this same time frame, $65 \%$ of the SNPR cells in kindled rats were firing in the bursting pattern.

The burst-firing response of nigral units in kindled rats was not a phenomenon common to all cells in the ventral brain stem. Nigral neurons firing in bursts temporally correlated to the EEG waveform were located throughout the rostral/caudal extent of the SN. On the other hand, of 15 cells recorded in the

\begin{tabular}{|c|c|c|c|}
\hline Animal & $\begin{array}{l}\text { Fraction of } \\
\text { cells bursting } \\
\text { time-locked } \\
\text { with the AD }\end{array}$ & $\begin{array}{l}\text { No. bursting } \\
\text { on EEG } \\
\text { spike }\end{array}$ & $\begin{array}{l}\text { No. } \\
\text { bursting } \\
\text { on EEG } \\
\text { slow } \\
\text { wave }\end{array}$ \\
\hline Naive dopamine & $2 / 6$ & 1 & 1 \\
\hline Kindled dopamine & $7 / 9$ & 6 & 1 \\
\hline Naive SNPR & $3 / 15^{*}$ & 3 & 0 \\
\hline Kindled SNPR & $19 / 22$ & 17 & 2 \\
\hline $\begin{array}{l}\text { Kindled reticular } \\
\text { formation }\end{array}$ & $1 / 15$ & 1 & 0 \\
\hline
\end{tabular}

The denominator in the fractions presented is the total number of cells within the group examined for burst-firing time-locked to the AD. The numerator is the number of cells found to burst time-locked with the EEG AD.

* A statistically significant difference between naive and kindled rats in the proportion of cells bursting synchronously with the $\mathrm{AD}(p<0.05$; chi-square). SNPR cells were more likely to fire in bursts during the EEG spikes than during the slow waves $(p<0.01$; sign test). Cells were included in this table only if they were held through the entire course of the AD. 

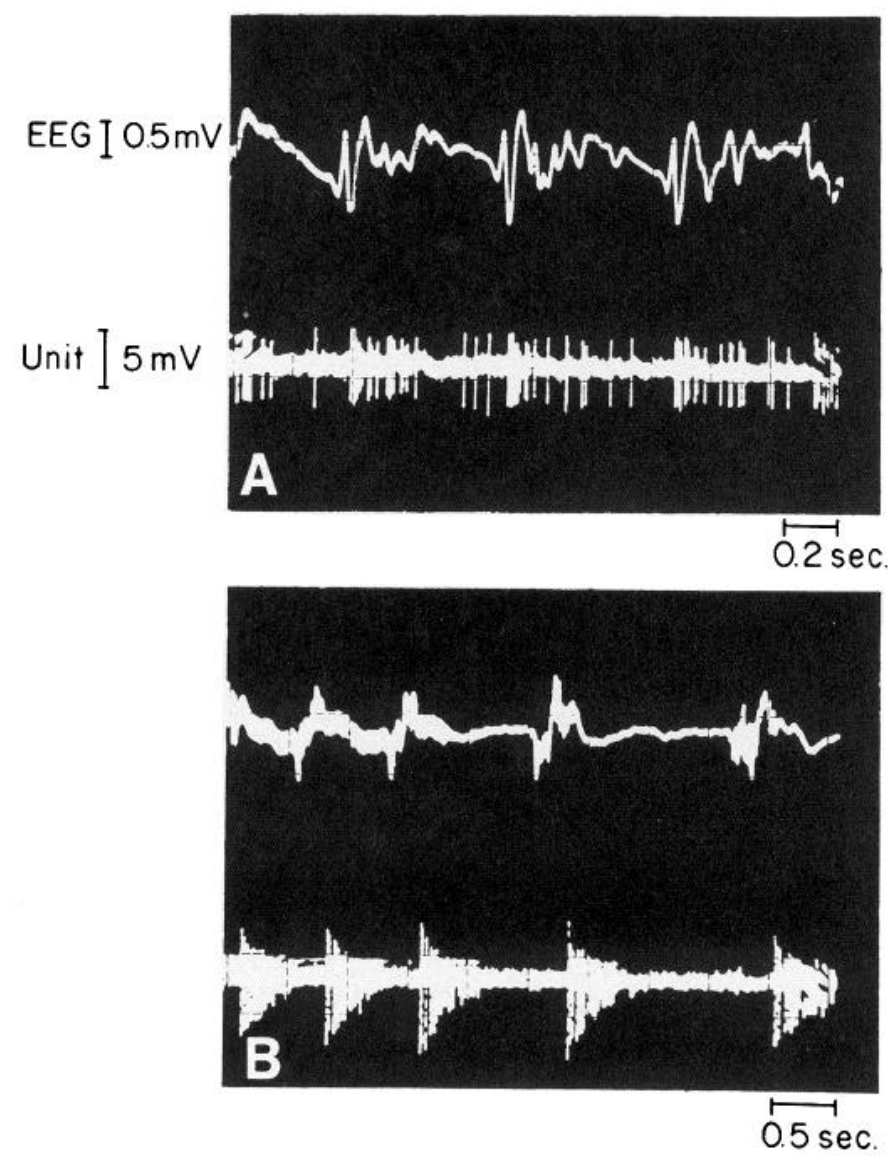

Figure 5. A, SNPR cell during the initial $10 \mathrm{sec}$ of AD. B, The same cell recorded $15 \mathrm{sec}$ later in the same AD. In each case, the upper trace is EEG recorded from the caudate and the lower trace is the unit recording.

pontine reticular formation caudal to the $\mathrm{SN}$, only 1 cell was found to fire in bursts during the AD (Table 1).

\section{Unit activity in the $S N$ : Rate}

No systematic attempt was made to evaluate the baseline firing rates of SN cells in the absence of electrical stimulation, since the purpose of these experiments was to determine the response of $\mathrm{SN}$ cells during $\mathrm{AD}$. On the basis of determinations made between seizures, we found no difference between the baseline firing rates of nigral units in kindled and naive rats (Table 2).

$\begin{aligned} & \text { Table 2. } \\
& \text { between seizures }\end{aligned}$
\begin{tabular}{lcc} 
Animal & SN dopamine & SN pars reticulata \\
\hline Naive & $10.3 \pm 3.8(9)$ & $21.2 \pm 3.9(22)$ \\
Kindled & $7.7 \pm 1.3(17)$ & $17.9 \pm 2.6(32)$
\end{tabular}

The numbers refer to the mean \pm SEM of the firing rate (spikes/sec) of SN neurons, calculated in the $50 \mathrm{sec}$ prior to initiating an AD. The values in parentheses refer to the number of cells examined. The difference in the number of cells reported in Tables 1 and 2 reflects the fact that only $65 \%$ of all recorded cells were held through the entire course of an AD. The firing rate of $\mathrm{SN}$ dopamine neurons reported here is faster than that typically observed (e.g., Grace and Bunney, 1984; Waszczak et al., 1980). This fast baseline firing rate may be the consequence of repeated $\mathrm{ADs}$ in the paralyzed state. The firing rate of $\mathrm{SN}$ dopamine neurons in naive and kindled rats that had not experienced $\mathrm{AD}$ was $4.8 \pm 0.8(n=5)$ and $7.3 \pm 1.4(n=12)$, respectively. There was no difference between naive and kindled cells in firing rates of nigral neurons (Student's $t$ test).
Table 3. Effect of nigral lesions on afterdischarge duration (ADD) in amygdala of naive and kindled animals

\begin{tabular}{|c|c|c|c|}
\hline \multicolumn{2}{|l|}{ Naive } & \multicolumn{2}{|l|}{ Kindled } \\
\hline Control & Nigral lesion & Control & Nigral lesion \\
\hline $9 \pm 2(10)$ & $10 \pm 1(9)$ & $89 \pm 5(10)$ & $26 \pm 10^{*}(10)$ \\
\hline
\end{tabular}

The numbers refer to the mean \pm SEM of ADD (in seconds). The numbers in parentheses refer to the number of animals in each group. The nigral lesions were produced with the neurotoxin NMDA, and were verified histologically. The data on kindled animals were reported by McNamara et al. (1984).

${ }^{*} p<0.001$; Student's $t$ test, 2-tailed.

Administration of trains of pulses at current intensities insufficient to evoke $A D$ produced no statistically significant change in the firing rate or pattern of SN neurons during the $10 \mathrm{sec}$ following the stimulation (paired $t$ test comparison of prestimulus firing rate to firing rate in the $10 \mathrm{sec}$ following stimulation: 7 SN dopamine cells, 7 SNPR cells). Similarly, administration of single pulses to the amygdala did not produce a change in rate or pattern of cells in the $10 \mathrm{sec}$ following the stimulation (3 SNPR cells through 10 pulses each).

\section{Lesion experiments}

Microinjection of $30 \mathrm{nmol}$ of NMDA into the SN produced lesions that encompassed as much as $95 \%$ of the total volume of the SN (range, 25-95\%) (Fig. 6). The behavioral manifestations of these lesions were the same as previously reported (McNamara et al., 1984). Lesions of the SN in naive animals did not suppress ADD (Table 3) or elevate ADT. ADTs in control and lesioned animals were $280 \pm 33(n=10)$ and $333 \pm$ $33(n=9) \mu \mathrm{A}$, respectively $(p>0.05)$. Furthermore, there was no statistically significant correlation between the degree of nigral destruction and the ADD or ADT based on linear-regression analyses. Thus, in contrast to the effect of SN lesions in kindled rats, the SN lesions in naive rats did not reduce ADD (Table $3)$.

\section{Discussion}

The 2 principal findings of this study were that (1) the majority of neurons recorded in the $\mathrm{SN}$ of kindled, but not naive, rats exhibited a striking change in their firing pattern during electrical seizures elicited by stimulation of amygdala, and (2) lesions of $\mathrm{SN}$ in naive animals, unlike kindled animals, did not suppress duration of $\mathrm{AD}$ in the amygdala.

\section{Activation of $S N$ neurons during AD: The burst-firing phenomenon}

Seizures evoked by stimulation of the amygdala in kindled rats produced a dramatic change in the firing pattern of both $\mathrm{SN}$ dopamine and SNPR cells. The firing pattern of SN neurons of kindled rats during AD consisted of the cells firing in bursts of action potentials, with the bursts exhibiting a clear temporal relationship to specific components of the AD in EEG recordings from caudate or amygdala.

Burst-firing of dopamine cells in the absence of seizures has been previously reported (Grace and Bunney, 1983, 1984). The burst-firing of SN dopamine neurons during seizures shares some of the characteristics of this previously reported phenomenon in that the action-potential amplitude diminished during the burst and there was broadening of the action-potential waveform (data not shown). However, the spike frequency of the dopamine cells in the seizure-related bursts was much higher than the spike frequency of the cells in bursts not related to seizures (Grace and Bunney, 1984). Burst-firing of SNPR cells in the absence of seizures has not been extensively studied. However, Kaniff et al. (1983) have reported the burst-firing of 


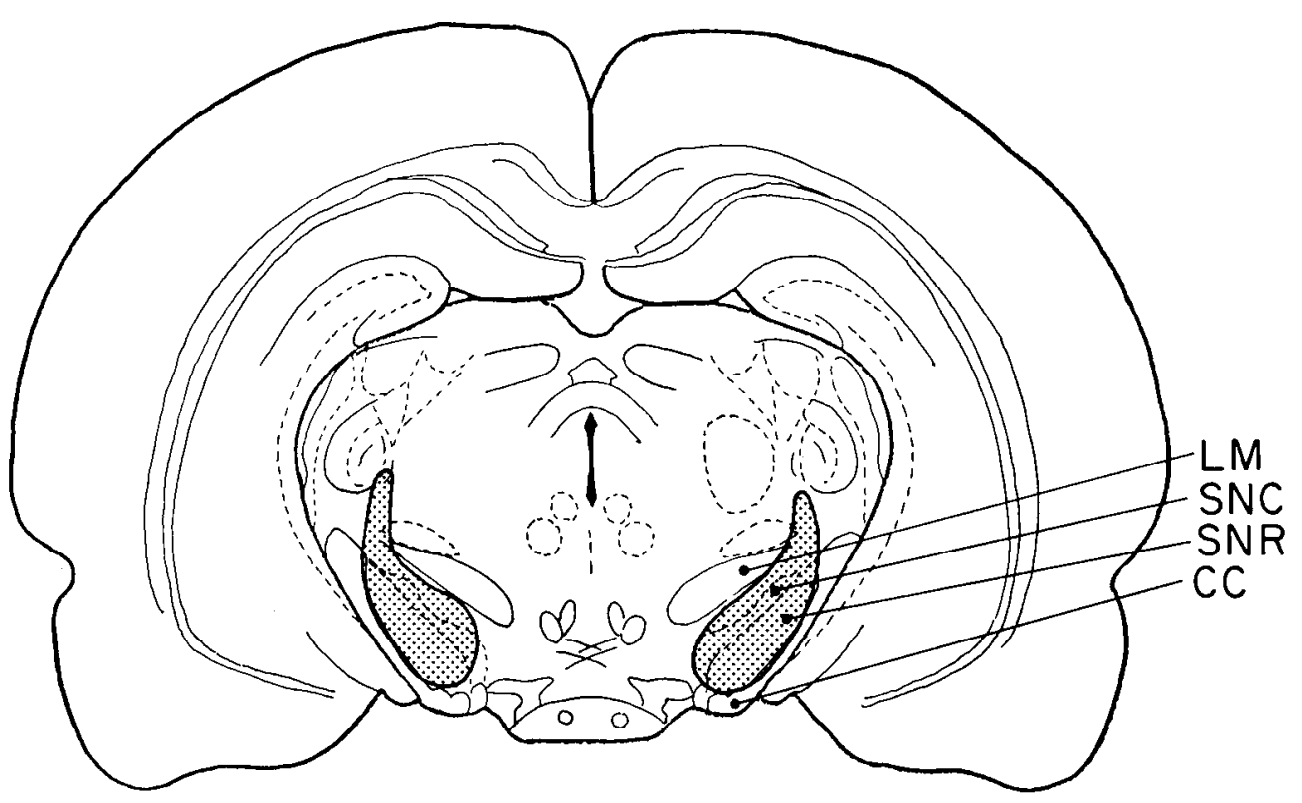

Figure 6. Reconstruction of NMDAinduced lesion. Stippled area represents the extent of the lesion. Figure is of a coronal section of a typical lesion. In this animal, $85 \%$ of the total $\mathrm{SN}$ volume was determined to be destroyed. $L M$, Medical lemniscus; SNC, substantia nigra pars compacta; $S N R$, substantia nigra pars reticulata; $C C$, crus cerebri.
SN neurons during penicillin-induced interictal spikes. These cells were histologically localized to the SN pars reticulata but their waveforms and firing rates were not given.

The temporal relationship between bursts of action potentials in SN neurons and AD recorded in amygdala or caudate indicates that the burst-firing of SN neurons is likely dependent upon synaptic input from structures extrinsic to $\mathrm{SN}$. The presence of $\mathrm{AD}$ in the striatum, together with the powerful influence of striatum on nigral excitability (Dray et al., 1976), suggests that the striatum is one extrinsic structure controlling nigral bursting during seizures. However, delineation of the structures actually responsible for controlling nigral bursting during seizures will require simultaneous unit or field recordings in multiple structures, together with interventional techniques such as lesions and microinjections.

The present results suggest that nigral output is dramatically increased during kindled seizures. The switch of nigral cells into the burst-firing mode supports the idea of enhanced synaptic output from SN neurons during seizures, since firing in burst patterns has been shown to result in a 1.5-2-fold increase in postsynaptic efficacy over equally spaced spikes of the same average frequency in crustacean motor neurons (Gillary and Kennedy, 1969). Moreover, there must be at least some degree of synchronization of neurons firing in the burst pattern, since most neurons firing in bursts did so during the polyspike complex of the EEG waveform during the AD. The synchronized bursting of populations of nigral neurons almost certainly enables the SN to exert a powerful influence on its targets during seizures.

\section{$S N$ activation: Role in propagation of kindled seizures}

Metabolic, electroencephalographic, and behavioral indices of seizure propagation demonstrate a more widespread propagation of seizure activity in kindled as compared to naive rats (for a review, see McNamara et al., 1985). The increased activation of SN neurons during AD in kindled animals indicates that the $\mathrm{SN}$ is one site of enhanced seizure propagation. The question of whether any of the behavioral aspects of kindled seizures can be directly ascribed to nigral activation, however, will require additional study.

The dramatic change in firing pattern of nigral neurons during $\mathrm{AD}$ in kindled animals leads us to hypothesize that the mechanism by which the $\mathrm{SN}$ facilitates seizure propagation involves synchronous burst-firing whereby the SN transmits seizure activity from rostral sites of origin to target structures. This hypothesis finds support in the results of electrophysiologic and lesion experiments. Seizures in kindled animals are associated with burst-firing of SN neurons and are suppressed by destruction of SN. In contrast to seizures in kindled animals, the electrical seizures in naive animals are not associated with nigral burst-firing and are not suppressed by nigral destruction. Therefore, a parallel emerges between nigral neuronal activation during seizures and the presence of a seizure-facilitatory action of SN.

Findings of other investigators indicate a parallel between nigral activation metabolically and a seizure-facilitatory action of SN. Engel et al. (1978) found that the SN exhibits increased 2-deoxyglucose uptake following AD in seizures elicited in kindled, but not naive, animals, indicating that nigral unit activation parallels metabolic activation in the kindling model. Increased 2-deoxyglucose uptake has also been found in the substantia nigra in association with seizures induced by the chemoconvulsants pentylenetetrazol and bicuculline (Ben-Ari et al., 1981). Interestingly, the SN has been found to exhibit a facilitatory action in both of these chemoconvulsant models, as well as in the kindling model.

The present results are consistent with the idea that burstfiring contributes to the prolongation and enhanced spread of AD. However, the results do not exclude the possibility that the tonic activity of SNPR neurons is crucial to the seizure-facilitatory mechanism. Indeed, the seizure facilitation by the nigra may involve both tonic activity and synchronous burst-firing. Recent studies have demonstrated that the conventional anticonvulsants, phenytoin and carbamazepine, suppress high-frequency firing in a number of neuronal preparations (Macdonald et al., 1985), yet do not affect tonic activity of nigral neurons after systemic administration (Waszczak et al., 1985). To test the proposed pivotal role of $\mathrm{SN}$ burst-firing in seizure propagation, we are examining the effects of nigral application of these drugs, both on behavioral seizures and nigral burst-firing.

\section{References}

Armitage, P. (1971) Statistical Methods in Medical Research, Blackwell Scientific Publications, Oxford, London, U.K.

Baker, H. J., J. R. Lindsey, and S. H. Weisbroth (1979) The Laboratory Rat. Volume I. Biology and Diseases, Academic, New York. 
Ben-Ari, Y., E. Tremblay, D. Riche, G. Ghilini, and R. Naquet (1981) Electrographic, clinical and pathological alterations following systemic administration of kainic acid, bicuculline or pentetrazole: Metabolic mapping using the deoxyglucose method with special reference to the pathology of epilepsy. Neuroscience 6: 1361-1391.

Engel, J., Jr., L. Wolfson, and L. Brown (1978) Anatomical correlates of electrical and behavioral events related to amygdaloid kindling. Ann. Neurol. 3: 538-544.

Dray, A., T. J. Goyne, and N. R. Oakley (1976) Caudate stimulation and substantia nigra activity in the rat. J. Physiol. (Lond.) 259:825849.

Garant, D. S., and K. Gale (1983) Lesions of substantia nigra protect against experimentally induced seizures. Brain Res. 273: 156-161.

Gillary, H. L., and D. Kennedy (1969) Neuromuscular effects of impulse pattern in a crustacean motoneuron. J. Neurophysiol. 32: 607612.

Goddard, G. V. (1967) Development of epileptic seizures through brain stimulation at low intensity. Nature 214: 1020-1021.

Goddard, G. V., D. C. McIntyre, and C. K. Leech (1969) A permanent change in brain function resulting from daily electrical stimulation. Exp. Neurol. 25: 295-330.

Gonzalez, L. P., and M. K. Hettinger (1984) Intranigral muscimol suppresses ethanol withdrawal seizures. Brain Res. 298: 163-166.

Grace, A. A., and B. S. Bunney (1983) Intracellular and extracellular electrophysiology of nigral dopaminergic neurons. I. Identification and characterization. Neuroscience 10:301-315.

Grace, A. A., and B. S. Bunney (1984) The control of firing pattern in nigral dopamine neurons: Burst firing. J. Neurosci. 4: 2877-2890.

Guyenet, P. G., and G. K. Aghajanian (1978) Antidromic identification of dopaminergic and other output neurons of the rat substantia nigra. Brain Res. 150: 69-84.

Hikosaka, O., and R. H. Wurtz (1985) Modifications of saccadic eye movement by GABA-related substances. II. Effect of muscimol in monkey substantia nigra pars reticulata. J. Neurophysiol. 53: 292308.
Iadarola, M. J., and K. Galc (1982) Substantia nigra: Site of anticonvulsant activity mediated by gamma-aminobutyric acid. Science 218 : 1237-1240.

Kaniff, T. E., C. M. Chuman, and E. J. Neafsey (1983) Substantia nigra single unit activity during penicillin-induced focal cortical epileptiform discharge in the rat. Brain Res. Bull. 11: 11-13.

Le Gal la Salle, G., M. Kaijima, and S. Feldblum (1983) Abortive amygdaloid kindled seizures following microinjection of gamma-vinyl-GABA in the vicinity of substantia nigra in rats. Neurosci. Lett. 36: 69-74.

Macdonald, R. L., M. J. McLean, and J. H. Skerritt (1985) Anticonvulsant drug mechanisms of action. Fed. Proc. 44: 2634-2639.

McNamara, J. O., L. C. Rigsbee, and M. T. Galloway (1983) Evidence that substantia nigra is crucial to the neural network of kindled seizures. Eur. J. Pharmacol. 88: 485-486.

McNamara, J. O., M. T. Galloway, L. C. Rigsbee, and C. Shin (1984) Evidence implicating substantia nigra in regulation of kindled seizure threshold. J. Neurosci. 4: 2410-2417.

McNamara, J. O., D. W. Bonhaus, B. J. Crain, R. L. Gellman, J. L. Giacchino, and C. Shin (1985) The kindling model of epilepsy: A critical review. CRC Crit. Rev. Clin. Neurobiol. 1: 341-393.

Moreland, A. F., W. E. Barkley, N. G. Bottiglieri, C. M. Lang, P. J. Manning, P. M. Newberne, S. P. Pakes, D. H. Ringler, and S. H. Weisbroth (1978) Guide for the Care and Use of Laboratory Animals, NIH publication No. 80-23, U.S. Department of Health, Education and Welfare, National Institutes of Health, Washington, DC

Racine, R. J. (1972) Modification of seizure activity by electrical stimulation: II. Motor seizure. Electroencephalogr. Clin. Neurophysiol. 32: 281-294.

Waszczak, B. L., N. Eng, and J. R. Walters (1980) Effect of muscimol and picrotoxin on single unit activity of substantia nigra neurons. Brain Res. 188: 185-197.

Waszczak, B. L., E. K. Lee, and J. R. Walters (1985) Effects of anticonvulsant drugs on single unit activity of substantia nigra (SN) pars reticulata neurons. Neurosci. Abstr. 11: 41. 